\title{
Research progress of rice husk ash in solidified soil
}

\author{
HAO Tong ${ }^{1}$, LIU Qian ${ }^{1}$, LENG Fa-Guang ${ }^{2}$, QIAO Tian-Long ${ }^{1}$ \\ ${ }^{1}$ School of Civil Engineering zhengzhou University, Zhengzhou 450000, China \\ ${ }^{2}$ China Academy of Building Research, Beijing 100013, China
}

\begin{abstract}
Rice husk ash is a kind of volcanic ash material with high silicon. This also provides a feasibility for rice husk ash as cement-based auxiliary cementing material. China is rich in rice husk resources, and the rice husk ash is stacked. Using rice husk ash ( RHA ) instead of traditional cementitious materials can effectively solve the environmental pollution caused by the accumulation of rice husk ash. Domestic and international scholar have added rice husk ash as mineral admixture to concrete, but the utilization rate is very low. In order to increase the added value of rice husk ash, the high silicon property of rice husk ash was used to solidify soil. The application range of solidified soil is wide, the requirements for materials are not high, and the functions are different, which can realize the extensive use of rice husk ash. This paper summarizes the literature on comprehensive utilization of rice husk ash at home and abroad, systematically expounds the physicochemical properties and production process of rice husk ash, introduces the application of rice husk ash in solidified soil, and points out the unsolved problems in this field, which provides a direction for the further development.
\end{abstract}

\section{Introduction}

China is a big rice country, according to rice production data released by the National Bureau of Statistics in 2020, rice production is 21.86 million tons, rice contains about $20 \%$ of rice husks[1]. Main Utilization Ways of Rice Husk[2-4]: One is to produce high value-added products based on the physical and chemical properties of rice husk. The second is to produce inorganic chemical products according to the silicon source in rice husk. The third is to use the high calorific value of rice husk as fuel for biomass power generation. In order to improve the added value of rice husk, the special physical and chemical properties of rice husk ash have entered people's vision.

Rice husk ash is commonly used to produce decontamination agent, adsorbent, desiccant, soil conditioner, cement of rice husk ash and raw materials of thermal insulation sheet[5-10]. In recent years, rice husk ash was added into soil as a curing agent to improve the performance of soil. Solidified soil is the use of some measures to consolidate the scattered soil into a solid with a certain strength[11].

Foreign research on rice husk ash started early. Ario muhammad[12]pointed out that rice husk ash is a kind of volcanic ash material, but because of its high silicon and lack of calcium, it is usually mixed with cement or lime, The rice husk ash, lime and clay are mixed, and the reinforced clay can be used as road base and bottom base materials. Muntohar[13]revealed that the mechanical properties and durability of rice husk ash reinforced soil were improved to varying degrees by adding some fiber materials. Domestic scholars initially added rice husk ash as admixture to cement concrete to study the impact on the performance of concrete. With the further understanding of the properties of rice husk ash, studies on the application of rice husk ash to soil reinforcement have gradually emerged. Yu Xiaoting[14] mixed rice husk ash into clay, and obtained that with the increase of rice husk ash content, the maximum dry density of the mixed soil decreased, and the optimum moisture content increased. Han[15] added rice husk ash to saline soil to study the engineering characteristics of improved soil.

\section{Production technology of rice husk ash}

\subsection{Production equipment of rice husk ash}

Compared with the traditional preparation of rice husk ash by muffle furnace combustion, the small-scale circulating fluidized bed is often used to produce rice husk ash, but the production efficiency is very low. Yu et al. [16]designed continuous rotary and intermittent box combustion furnaces to achieve semi-industrial production of rice husk ash. The rice husk ash obtained in this way has high volcanic activity. Liu Yuanchun, etc. [17]Liu Yuanchun et al. use large step inclined reciprocating grate semi-suspension combustion hot water boiler combustion rice husk, but rice husk is not easy to burn out, rice husk ash separation rate is low, high carbon

\footnotetext{
* Corresponding author: Liu qian 2904831806@qq.com
} 
content. Ouyang Dong et al. [18] used his own research capacity of $1 \times 10^{3} \mathrm{~L}$ incinerator, furnace temperature and air content can be changed to produce high silicon content and high activity of rice husk ash. Chen Pei et al. [19]Chen Pei et al. used fluidized bed combustion pretreatment of rice husk, the rice husk ash high silicon high activity, loose particles, non-bonding condition. Jia Yu[20]adopts rotary floating combustion hot blast stove to overcome the characteristics of low combustion efficiency and high carbon content in grate and reduce pollution, which has good environmental benefits.

\subsection{Combustion temperature of rice husk ash}

The rice husk ash can be burned under controlled low temperature conditions to obtain high activity, containing a large number of amorphous $\mathrm{SiO}_{2}$. When the temperature is too high, the crystal form of $\mathrm{SiO}_{2}$ changes from amorphous to crystal, and the utilization value is lost. Gong Xiaoqiang[21]calcined rice husk ash at different temperatures of $400^{\circ} \mathrm{C}, 600^{\circ} \mathrm{C}$ and $800^{\circ} \mathrm{C}$, which proved that with the increase of temperature, the surface unburned substances were less. At $400{ }^{\circ} \mathrm{C}$, the outer surface of rice husk ash is basically complete. At $600{ }^{\circ} \mathrm{C}$, the surface is full of spherical substances and relatively complete. Temperature to $800^{\circ} \mathrm{C}$, showing a molten shrinkage ( see figure 1 ). Hongtao[22]Sun Qingwen[23]Jiang Xinhui[24]pointed out that when the combustion temperature is lower than $600{ }^{\circ} \mathrm{C}$, amorphous $\mathrm{SiO}_{2}$ is the main component in rice husk ash. Ouyangdong[3]compared the low-temperature combustion rice husk ash with silica fume, and obtained that the X-ray diffraction patterns of low-temperature rice husk ash and silica fume were similar. The two substances were composed of amorphous $\mathrm{SiO}_{2}$, and they were mixed with $\mathrm{Ca}(\mathrm{OH})_{2}$ according to the ratio of $3: 1$. XRD analysis showed that the ability of low-temperature rice husk ash to absorb $\mathrm{Ca}(\mathrm{OH})_{2}$ could be equivalent to that of silica fume. Although scholars have a slight controversy on the optimal combustion temperature of rice husk ash, they have basically a relatively unified understanding of the calcination temperature that maintains the high activity of rice husk ash. It is generally believed that the ash obtained from the combustion of rice husk at about $600{ }^{\circ} \mathrm{C}$ contains more than $90 \%$ amorphous $\mathrm{SiO}_{2}$. When the temperature is above $650{ }^{\circ} \mathrm{C}$, the content of crystalline $\mathrm{SiO}_{2}$ begins to increase. When the temperature reaches $800{ }^{\circ} \mathrm{C}$, amorphous $\mathrm{SiO}_{2}$ content is only about $50 \%$. When the temperature is above $950{ }^{\circ} \mathrm{C}$, amorphous $\mathrm{SiO}_{2}$ almost disappears.

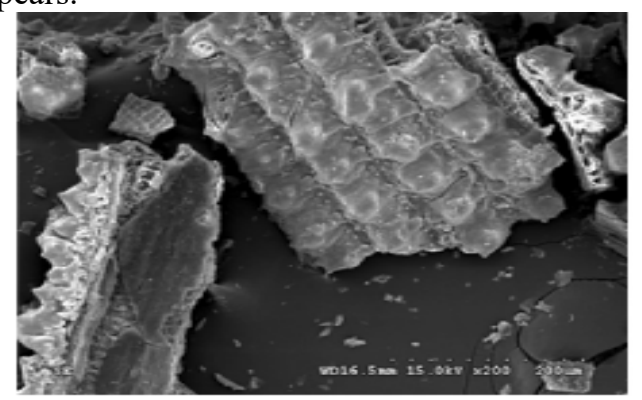

$400^{\circ} \mathrm{C}$

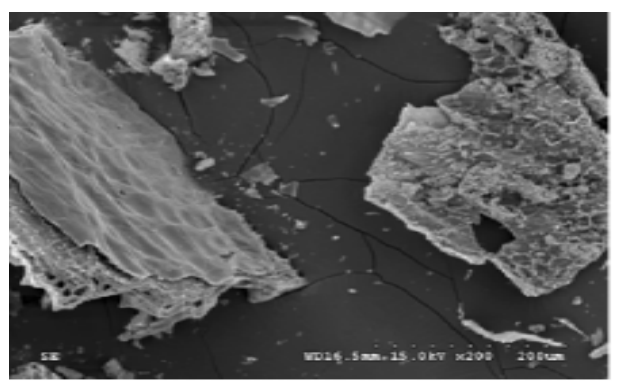

$600^{\circ} \mathrm{C}$

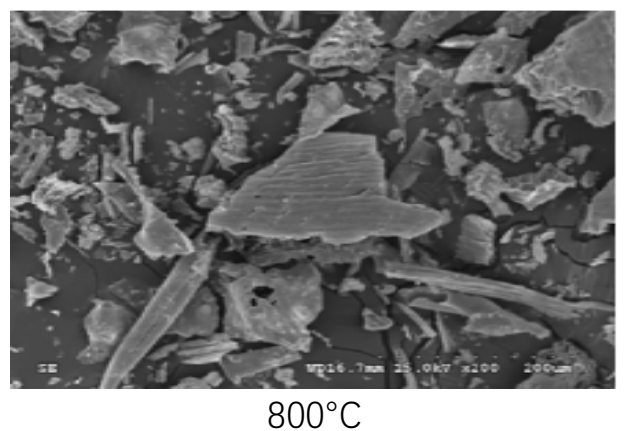

Figure 1. SEM images of rice husk ash samples ( 200 times )[21]

\section{Properties of rice husk ash}

\subsection{Physical properties of rice husk ash}

The physical properties of rice husk ash are affected by many factors. Relative density of rice husk ash ranged from 2. 05 to 2.53 and specific surface area ranged from 500 to $1000 \mathrm{~cm}^{2} / \mathrm{kg}$ [25]. Kothandaraman[26] found that the gravity of rice husk ash could qualitatively indicate its crystalline state. The greater the gravity of rice husk ash was, the more the amorphous substance content was. Therefore, the gravity of rice husk ash should be controlled at $1.1-1.9 \mathrm{kN} / \mathrm{m}^{3}$.

Most of the rice husk ash is gray black flake, irregular shape, which is due to the carbon content in the rice husk ash. Krishnarao [27]found that potassium in rice husk ash was an important cause of black particles. Potassium could melt the surface of $\mathrm{SiO}_{2}$ and transform amorphous $\mathrm{SiO}_{2}$ to crystalline form. When the combustion temperature is too high, potassium will eutectic with $\mathrm{SiO}_{2}$, and melt on the surface of rice husk, which hinders the further reaction of carbon in rice husk. Gong Xiaoqiang [21]concluded that the color of rice husk ash would change from gray-black to gray-white with the increase of temperature. This is because with the increase of temperature, the combustion of rice husk ash is more sufficient, the combustible material decreases, and the carbon content decreases.

\subsection{Chemical properties of rice husk ash}

The chemical composition of rice husk ash varies with combustion equipment, combustion temperature, combustion time and geographical location. The main chemical composition of rice husk ash is $\mathrm{SiO}_{2}$, and the content range is from $49.7 \%$ to $95.41 \%$. The following 
is the chemical composition of rice husk ash obtained from some representative literatures. [26-36] (See table 1).

Table1. Main chemical components of rice husk ash

\begin{tabular}{|c|c|c|c|c|c|}
\hline $\begin{array}{l}\text { Chemical } \\
\text { composition }\end{array}$ & $\begin{array}{l}\mathrm{SiO}_{2} \\
(\%)\end{array}$ & $\begin{array}{l}\mathrm{Al}_{2} \mathrm{O}_{3} \\
(\%)\end{array}$ & $\begin{array}{l}\mathrm{Fe}_{2} \mathrm{O}_{3} \\
(\%)\end{array}$ & $\begin{array}{l}\mathrm{CaO} \\
(\%)\end{array}$ & $\begin{array}{l}\mathrm{MgO} \\
(\%)\end{array}$ \\
\hline $\begin{array}{l}\text { Rungroj } \\
\text { Piyaphant }\end{array}$ & 93.18 & 0.31 & 0.26 & 0.47 & 0.23 \\
\hline $\begin{array}{l}\text { N. F. Mohd } \\
\text { Joharudin }\end{array}$ & 87.23 & 0.35 & 0.23 & 1.74 & 1.23 \\
\hline Indian rice mill & 93.26 & 4. 10 & 0.08 & 0.18 & 0.00 \\
\hline Patel Kameshwar & 82.70 & 0.58 & 0.39 & 0.75 & 0.27 \\
\hline $\begin{array}{l}\text { Tarun Kumar } \\
\text { Naiya }\end{array}$ & 84.30 & 0.30 & 0.60 & 1.40 & 0.50 \\
\hline Hossein Moayedi & 96.2 & - & 0.05 & 0.13 & 0.36 \\
\hline S. K. Antiohos & 89.05 & 0.25 & 0.41 & 0.85 & 0.81 \\
\hline J. G. Tapali & 86.50 & 0.92 & 0.56 & 1. 12 & 1. 30 \\
\hline Antiohos, S K & 89.47 & 0.18 & 0.25 & 1. 10 & 0.44 \\
\hline Papadakis, V G & 93.15 & 0.13 & 0.18 & 0.89 & 0.40 \\
\hline \multirow[t]{2}{*}{ A. Muthadhi $\bullet$ S. } & 89.47 & - & 0.62 & 2. 69 & 1. 16 \\
\hline & 90.20 & 0.26 & 0.03 & 0.07 & 0.03 \\
\hline \multirow{3}{*}{ R. V. Krishnarao } & 92.20 & 0.07 & 0.01 & 0.00 & 0.01 \\
\hline & 89.80 & 0.29 & 0.04 & 0.06 & 0.03 \\
\hline & 61.90 & 1. 20 & 11.4 & 5.40 & 1.40 \\
\hline \multirow{2}{*}{ Y. O. Abiodun } & 62.60 & 3.30 & 5. 10 & 6.90 & 3.40 \\
\hline & 59.50 & 2. 10 & 8.80 & 7.30 & 2.20 \\
\hline
\end{tabular}

\subsection{Microstructure of rice husk ash}

The microstructure of rice husk ash is divided into three layers. Chen Pei[37]used SEM to find that the outer surface of rice husk ash was dense, smooth, angular and orderly arranged. The interlayer was composed of vertically and horizontally crisscrossed plate-like structure with uniform spacing. The size of tens of microns was honeycomb pore structure. The inner surface was flat sheet structure ( see Fig. 2 ). This is consistent with the findings of Zeng Xiaoping[5], Kameshwar P[38]. Ou yangdong[39] used TEM to reveal that rice husk ash contains a large number of nano-scale pores ( $50 \mathrm{~nm}$ ) formed by the very close cohesion of $\mathrm{SiO}_{2}$ gel particles in addition to micro-scale ( $10 \mathrm{um}$ ) honeycomb pores, which is also the reason for the large specific surface area of rice husk ash(see Fig. 3).

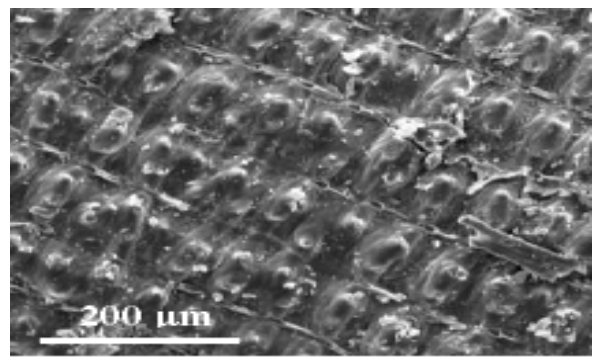

external surface
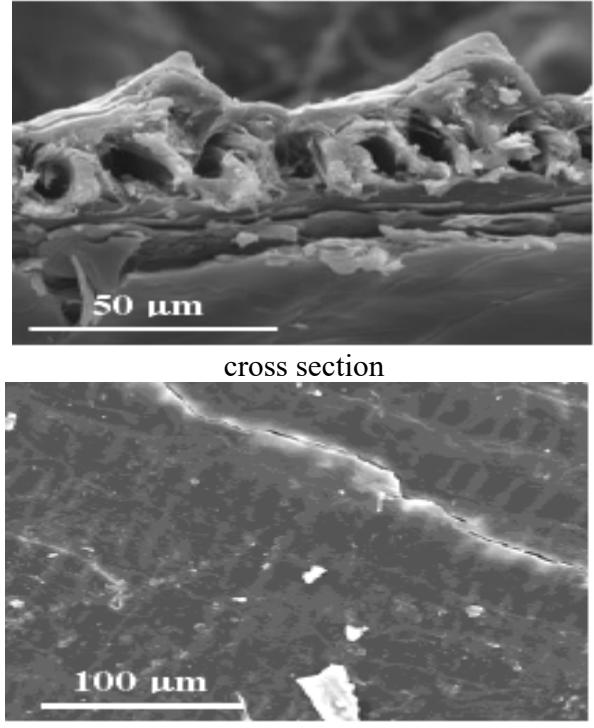

internal surface

Figure 2. Micromorphology of rice husk ash[37]

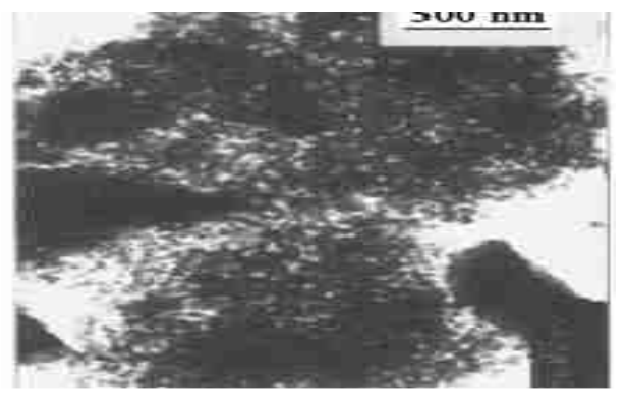

Rice - grained particles of rice husk ash particles

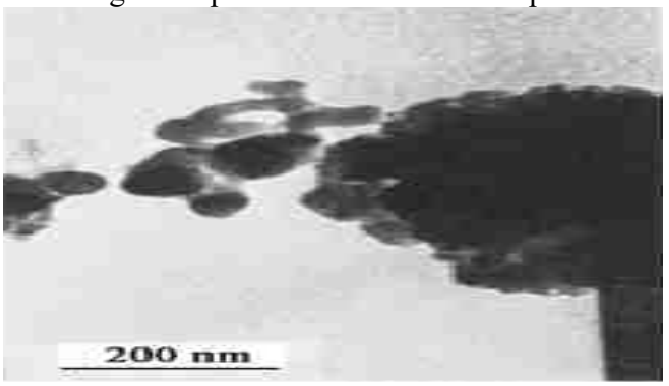

Granular particle magnification of rice

Figure 3. TEM images of rice husk ash

\section{Application of Rice Husk Ash in Solidified Soil}

\subsection{Rice husk ash solidified soil as base}

At present, there are abundant studies on the application of rice husk ash as admixture to concrete. In recent years, some scholars have begun to apply rice husk ash to soil solidification. The traditional pavement base material uses cement gravel. With the expansion of the scale of transportation infrastructure construction, the price of raw materials has risen rapidly, and excessive exploitation is not conducive to environmental protection. B. Suneel Kumar[40] studied the mixture of rice husk ash and lime to solidify cohesive soil, and concluded that the combination of $6 \%$ lime and $10 \%$ RHA ( rice husk ash ) 
improved CBR. Leonardo Behaket al. [41] used RHA and lime modified silty soil as pavement base. The soil base layer modified by RHA and lime showed good performance on low volume road, and also showed good performance after 20 months, which was better than the traditional pavement with fine sand structure. Muthu Lakshmi S. [42] used RHA and lime to enhance the strength of clay subgrade. Si Zehua[43] uses $20 \%$ RHA + $10 \%$ cement $+0.3 \%$ polypropylene fiber to solidify carbonated subgrade soil. $\mathrm{SiO}_{2}$ in RHA inhibits the chemical reaction of cement hydration products and $\mathrm{Cl}$ and $\mathrm{SO}_{4}^{2-}$ in saline soil, and reduces the formation of lowstrength Friedel salt ettringite and ettringite. The compressive strength, CBR and resilient modulus of each grade of road base meet the requirements of the specification. Roy Aparna[44] used RHA and cement to solidify subgrade cohesive soil. The results showed that with the increase of RHA and cement ratio, the optimum moisture content and CBR increased, and the maximum dry density decreased. Basha et al[45]added RHA to cement stabilized soil, significantly improved the CBR value. Liu Yuyi[46]Guo Shuai[47] used RHA and carbide slag to solidify expansive soil at the mass ratio of $65: 35$, and carried out compaction, unconfined compression, CBR, shear strength, dry shrinkage and other experiments. It proved that the performance of rice husk ash- carbide slag composite cementitious material was excellent, and the performance of solidified expansive soil met the requirements of road base. Zhang Xinyu[48] uses $20 \%$ steel slag $+5 \%$ quicklime $+10 \%$ RHA to improve expansive soil. The physical properties, mechanical properties and swelling and shrinkage of the improved soil are significantly improved. Subgrade paving can reduce materials and save costs. Anjani Kumar Yadav[49] used RHA, bagasse ash and cow dung ash to stabilize subgrade alluvial soil. After solidification, the CBR of soil was improved, the dry density was reduced and the maximum water content was increased. J. E. Sani[50]studied the influence of rice husk ash and sisal fiber on the laterite of road building materials.

\subsection{Effect of solidified soil from rice husk ash on leaching of heavy metals}

The solidification of heavy metal contaminated soil with rice husk ash not only brings economic benefits, but also usually improves the durability and sulfate resistance of solidified soil. In addition, the volcanic ash reaction will continue for a long time, resulting in a long-term stability effect. The fixation mechanisms of heavy metals are mainly adsorption, precipitation, complexation, encapsulation, etc[51]. Metals in sludge or soil can be combined into $\mathrm{C}-\mathrm{S}-\mathrm{H}$ to form $\mathrm{C}-\mathrm{S}-\mathrm{M}-\mathrm{H}$ or to form complex silicates directly through M-O-Si bonds[52-62].

Rungroj Piyaphanuwatet al[63] used rice husk ash and carbide slag to stabilize and solidify zinc electroplating sludge. The weight percentage of carbide slag and rice husk ash was $60: 40$, and then the activators $\mathrm{Na}_{2} \mathrm{SiO}_{3}$ and $\mathrm{Na}_{2} \mathrm{CO}_{3}$ were added to improve the strength and durability of solidified sludge, which effectively reduced the leaching of metal substances. The treated electroplating sludge was used for soil landfill, which effectively reduced the pollution to the surrounding environment. Chun-Yang Yin et al[64]used OPC and RHA to solidify lead contaminated soil. The results showed that when the content of RHA increased from 0 to $30 \%$, the leaching rate of lead in the treated samples decreased accordingly, and the lead concentration decreased from $3.70 \mathrm{mg} / \mathrm{L}$ to $1.06 \mathrm{mg} / \mathrm{L}$. From the XRD spectrum, it was concluded that lead nitrate was precipitated on the surface of C-S-H as a metal hydration phase or metal hydroxide, which reduced the solubility. Abraham C. F. Chiu[65] used rice husk ash instead of $20 \%-40 \%$ cement to solidify artificially prepared heavy metal contaminated soil. The results showed that compared with pure cement solidified contaminated soil, the incorporation of rice husk ash significantly reduced the diffusion coefficient of $\mathrm{Pb}$ and $\mathrm{Cu}$ content samples. With the increase of rice husk ash content, the fixation effect of $\mathrm{Pb}$ was significant, but the effect of $\mathrm{Cu}$ was slightly poor.

\section{Conclusions}

The comprehensive utilization of rice husk ash has great prospects for development. It not only deals with industrial solid waste, but also greatly reduces the cost. Despite the high added value of rice husk ash, we still face several major challenges:

The supply of rice husk ash to meet the requirements is extremely low, and rice husk ash has higher requirements for combustion conditions. Underburning can make the carbon content of rice husk ash extremely high, and overburning can make the crystal morphology of rice husk ash from crystallization to amorphous.

In China, the utilization of rice husk ash started relatively late, and it is rarely applied to the ranks of solidified soil. The solidified soil of rice husk ash is not only lack of research on macro mechanical properties, but also lack of research on micro mechanism.

The performance of rice husk ash is easily affected by the types of rice husk, and there are few studies on the related properties of different types of rice husk ash.

The properties of rice husk ash are comparable to silica fume, but rice husk ash lacks relevant standards to guide our engineering application.

\section{References}

1. Pode, R. Renewable \& sustainable energy reviews, 53: page 1468-1485 (2016)

2. ZhaoLi ming,Wang Shiqiang, Gu Chunmei, etc.Heilongjiang Agricultural Science,(03), page147151 (2017)

3. Lu Shiyang, Shenyang University of Chemical Technology. Page 65,(2019)

4. Liu Wenlong et al., University Chemistry, 33 ( 07 ) : page $90-95,(2018)$

5. Zeng Xiaoping, Science and Technology, ( 21 ) : Page 120, (2018) 
6. Xiao Lufei et al., Chemical World, 61 ( 07 ) : page. 457-464, (2020)

7. Yang Zhonghao, Heilongjiang Papermaking, 44 ( 03 ) : Page 6-8, (2016)

8. Mingyang et al., cement engineering, ( 03 ) : page 69$72,(2015)$

9. Li and Cheng, Fujian Building Materials, ( 11 ) : pages 13 - 14, (2013)

10. Liu Yan, Jilin University. Page 155, (2013)

11. Zhou Yongxiang and Yan Peiyu, Journal of Railway Science and Engineering, 3 ( 4 ) : 35-40, (2006)

12. A, M. APreliminary Study. (2007)

13. Muntohar, A. S. , et al. Journal of materials in civil engineering, 25(9): page 1260-1270, (2013)

14. Yu, 2019, Hubei University of Technology. Page 67.

15. Korea Aerospace, Lanzhou University of Technology. Page 101. (2020)

16. Yu et al., Journal of Wuhan University of Technology, ( 01 ) : page $15-18,(2003)$

17. Liu Yuanchun et al., industrial boiler, ( 06 ) : page 26$29,(2009)$

18. Ou yangdong, South China University of Technology, (1997)

19. Chen Pei, Wu O and Bie Rushan, Journal of Harbin Institute of Technology, 51 ( 03 ) : page. 46-54,(2019)

20. Jia Yu, Qin Feng and Xiao Yanmin, modern food, ( 02 ) : page 95-97,(2017)

21. Gong Xiaoqiang et al., Journal of Wuhan University of Light Industry, 37 ( 01 ) : page 51 - 55,(2018)

22. Li Hongtao et al., Journal of Agricultural Machinery, 44 ( 04 ) : page 131-136,(2013)

23. Sun Qingwen, Xu Kejing and Guo Yanqing, Chinese ceramics, 48 ( 07 ) :page 1-6(2012)

24. Jiang Xinhui, 2010, Harbin Institute of Technology.

25. Wang Zhiwen and Li Bixiong, Material Report, 34 ( 09 ) : Page 9003-9011.(2010)

26. Muthadhi, A. and S. Kothandaraman, Materials and structures, 43(9): page 1303-1315.(2010)

27. Krishnarao, R. V. , J. Subrahmanyam and T. Jagadish Kumar,Journal of the European Ceramic Society, 21(1): page 99-104,(2001)

28. Moayedi, H. A. H. M. , et al. Journal of Cleaner Production, 237(2019).

29. Aliyu, M. K. , et al. ,Water and environment journal : WEJ, 34(S1): page 229-238,(2020)

30. Piyaphanuwat, R. and S. Asavapisit, Environmental progress \& sustainable energy,37(6):page 19651972,(2018)

31. Mohd Joharudin, N. F. , et al.50(3): page 283288,(2019)

32. Kameshwar, P. , et al. Structural concrete : journal of the FIB, 22(S1): p. E501-E513,(2021)
33. Naiya, T. K. , A. K. Bhattacharya and S. K. Das, Environmental progress \& sustainable energy, 28(4): page 535-546,(2009)

34. Antiohos, S. K. , et al. Construction \& building materials, 49: page 455-463,(2013)

35. Antiohos, S. K. , V. G. Papadakis and S. Tsimas,Cement and Concrete Research, 61-62: page 20-27,(2014)

36. Abiodun, Y. O. and A. A. Jimoh, Nigerian journal of technology, 37(1): page 71,(2018)

37. Chen, Harbin Institute of Technology. Page 142,(2019)

38. Kameshwar, P. , et al. journal of the FIB,(2020)

39. Ouyangdong and Chen Kai, Journal of Materials Science and Engineering, ( 05 ), page 647-650,(2003)

40. B. Suneel Kumar, T. V. P. IJETT Journal,11, page 1(2014)

41. Behak, L. and M. Musso, Transportation Research Procedia, 18: page 93-99(2016)

42. Muthu Lakshmi, S.et al. Materials today : proceedings, (2021)

43. Siserhua, Jilin University. Page 91,(2020)

44. Roy, A. International Journal of Civil Engineering Research, 5: page 49-54,(2014)

45. Basha, E. A. , et al. Construction \& building materials, 19(6), page 448-453(2005)

46. Liu Yuyi, China University of Mining and Technology. Page 221,(2019)

47. Guo Shuo, Highway Engineering, 45 ( 03 ), Page 210215.(2020)

48. Zhang Xinyu.Road Engineering. Page 20-24, ( 2018 )

49. Kumar Yadav, A. , et al. International Journal of Pavement Research and Technology,10(3):page 254-261,(2017)

50. Sani, J. E. , P. Yohanna and I. A. Chukwujama, Engineering sciences, 32(1): page 11-18,(2020)

51. Tang Dengyong et al., China Rural Water Conservancy and Hydropower, ( 11 ) : page 68-72, (2017)

52. Wang, F. , et al. Journal of hazardous materials, 300, page $451-458,(2015)$

53. Nowak, B. , P. Aschenbrenner and F. Winter, Fuel processing technology, 105: page 195-201,(2013)

54. Cubukcuoglu, B. and S. K. Ouki, Chemosphere, 86(8): page 789-96, (2012)

55. Li, X. , et al. Waste Manag, 34(12): page 2494504,(2014)

56. Tan Jintao et al., China Environmental Science, 40 ( 07 ) ,page 3054-3060,(2020)

57. Lin Meishan, Chen Yu and Chen Ting, Journal of Wuhan University of Engineering, 42 (01), page 38$44,(2020)$

58. Liu Ling and Guan Chang, science and technology innovation, ( 31 ), page 42-43,(2019)

59. Liu Ling et al., Science and Technology Innovation, ( 30 ), page 55-56,(2019) 
60. Liu Qi et al., Chemical Research and Application, 31 ( 08 ) ,page 1482 - 1491,(2019)

61. Zuo Hai Qiang, industrial water and wastewater, 43 ( 04 ) : page 58 - 61,(2012)

62. Chiu, A. , et al. J Hazard Mater, 371, page 6271,(2019)

63. Piyaphanuwat,R.and S. Asavapisit, Environmental progress \& sustainable energy, 37(6), page 1965-1972, (2018)

64. Yin, C. Y., H. B. Mahmud and M. G. Shaaban, J Hazard Mater, 137(3): page 1758-64,(2006)

65. Chiu, A. C. F. , et al. Journal of hazardous materials, 371, page 62-71,(2019) 